Original Article

\title{
ASSESSMENT OF DRUG UTILIZATION AMONG PEDIATRIC PATIENTS IN PRIVATE CLINIC AND PUBLIC HOSPITAL OF BANGLADESH
}

\author{
AHSAN UDDIN ${ }^{1}$, TRIPTI RANI PAUL ${ }^{2}$, MONALISA MONWAR ${ }^{2}$, SHAHIN SARKER ${ }^{3}$, CHAND SULTANA $^{4}$, MIR IMAM $^{4}$ \\ IBNE WAHED ${ }^{*}$
}

1Department of Pharmacy, University of Rajshahi, Rajshahi 6205, Bangladesh, 2Department of Pharmacy, Varendra University, Rajshahi 6204, Bangladesh, 3Department of Pharmacy, Jashore University of Science and Technology, Jashore 7803, Bangladesh, ${ }^{4}$ Department of Pharmacy, Mawlana Bhasani Science and Technology University, Tangail 1901, Bangladesh

Email: drmirimam@gmail.com

Received: 17 Aug 2018, Revised and Accepted: 20 Jul 2020

\begin{abstract}
Objective: Aim of the study was to assess drug utilization among pediatric patients in both private practice and hospital settings in Rajshahi city, Bangladesh.

Methods: This observational study was conducted during a period of two months (March to April) in 2017. Prescriptions were randomly collected from patients and recorded in a predesigned questionnaire form. The data analysis was carried out by using a statistical software package GraphPad Prism.

Results: The study involved a total of 185 patients, of which $62.70 \%$ were male and $37.30 \%$ were female. The patient's age ranges from 1 mo- 12 y and highest number of patients visited physicians belong to group 1 mo-1 y (47.57\%). Most commonly occurring disease conditions were pneumonia $(24 \%)$, the leading cause of hospitalizations among the children's age group of 1 mo- $1 \mathrm{y}$. The results indicated that physician's handwriting was not clear and legible in $50(27.03 \%)$ prescriptions. A total of 468 drugs were prescribed with an average of 2.53 per prescription However, none of the drugs were prescribed by generic name. The most commonly prescribed drugs were antibiotics 173 (93.5\%). About $78 \%$ patients were exposed to antibiotics, of which single antibiotic was prescribed in $116(62.70 \%)$ and two antibiotics in $23(12.43 \%)$ prescriptions. Among the drugs, NSAIDS 65 (35.14\%), anti-histamine 57 (30.81\%), anti-asthmatic $49(26.49 \%)$ drugs were assigned in prescriptions followed by vitamin and minerals 51 (27.57\%). Steroids $57(30.81 \%)$ and hypnotics $26(14.05 \%)$ were also accounted in many prescriptions. Interestingly, antibiotics were indiscriminately prescribed in private practices without any bacteriological examinations, whereas in hospital settings, most of the treatment was initiated after culture and sensitivity tests.
\end{abstract}

Conclusion: Children were highly exposed to antibiotics, steroids and hypnotics in both private practice and hospital settings. So Medical practitioners should be aware of current guidelines for prescriptions of antibiotics and drugs in child.

Keywords: Drug utilization, Pediatric, Antibiotic, Steroid, Hypnotics, Polypharmacy

(C) 2020 The Authors. Published by Innovare Academic Sciences Pvt Ltd. This is an open access article under the CC BY license (http://creativecommons.org/licenses/by/4.0/) DOI: http://dx.doi.org/10.22159/ijpps.2020v12i9.29186. Journal homepage: https://innovareacademics.in/journals/index.php/ijpps.

\section{INTRODUCTION}

Children are the most vulnerable population and susceptible to microbial infections. The pharmacokinetic characteristic of the drug differs with sex and age. Drug metabolizing capacities of children is lower than that of adults and are frequently encountering adverse drug reactions $[1,2]$. Several drug utilization studies were carried out around the globe; however, a very few study provides information on drug use pattern in infants and children $[3,4]$ Pediatric are frequently suffering from common illnesses such as cold, fever and diarrhea. Although most of the conditions are selflimiting but are often managed by drugs, which are inappropriate and practice of polypharmacy were also observed [5]. Currently, antibiotics are the most commonly prescribed and lifesaving drugs in hospitals settings [6]. However, there are growing evidences of developing antimicrobial resistance due to misuse or overuse of antibiotics in Bangladesh [7, 8]. Studies reported that in both developed and developing countries more than $50 \%$ of children received antibiotics as recommended by the physicians [9]. In many cases, antibiotics were unnecessarily prescribed without the evidence of bacterial infections [10]. Thus, prescription of antibiotics increases $30-50 \%$ of the total medical costs as reported in studies conducted in India and Bangladesh $[11,12]$. In fact, irrational and inappropriate prescribing of drugs is a recognized problem of the health care delivery system worldwide [13]

Now a day, drug utilization studies are found to be a useful tool for the implementation of rational use of drugs in health care settings. To ensure the rational use of drugs, a drug must be safe, effective and prescribed for specific therapeutic purpose with the correct dose, dosage form and regimen. In addition, it must be easily available at low and affordable cost. International Network on the Rational Use of Drugs (INRUD) in collaboration with WHO, developed indicators that provides guidelines for the assessment of drug use practices and thus, suggesting remedial measures and improvement of policies [14]. In fact, safe and effective drug therapy is possible only when patients are well informed about disease, drugs and the purpose of medication [15]. Recently, it has been reported that children are most commonly encountering the problem of multiple drug therapy with inappropriate drugs, dose and dosage regimens [16]. Unfortunately, children are rarely involved and/or participate in clinical trials due to ethical issues and in some cases, the effect of drugs in children are often inadequate [4, 17]. Therefore, studies are required to assess the attitude of the physician's prescribing pattern of drugs among child and infants. The aim of the present study was to investigate drug use pattern in pediatrics by the physicians practicing in both private and hospital settings in Rajshahi city of Bangladesh.

\section{MATERIALS AND METHODS}

Study site

The prospective study was conducted in a divisional city, Rajshahi in the northern part of the country, whereby a number of child specialists practices in private chamber and also in Rajshahi Medical College and Hospitals (RMCH), one of the largest tertiary care teaching hospital in Bangladesh. 


\section{Study period}

Prescriptions were randomly collected from patients and/or their guardians during the period from March 2017 to April 2017.

\section{Study population}

Patients with age ranges from 1month-12years visiting physicians in a private chamber and/or RMCH during the period were included in the study.

\section{Development of patient data entry form}

A self-designed data entry form consisting of a patient's demographic information, clinical diagnosis, medical history was used for the collection of primary data.

\section{Evaluation parameters}

Demographic characteristics of the patients, common diseases from which patients suffering, diagnostic tests, the average number of drugs per prescription, percentage of drugs prescribed by generic name, percentage of prescription with antibiotics, types of antibiotic prescribed, the average age range of patient utilizing antibiotics, the average number of antibiotics per prescription were evaluated.

\section{Selection of patients \\ Inclusion Criteria}

Patients under the treatment and supervision of a consultant physician, and patient's personal and prescription information were recorded.

\section{Exclusion Criteria}

Prescriptions with incomplete information were excluded.

\section{RESULTS}

A total of 185 (out of 201) prescriptions were evaluated of which $135(54 \%)$ were from private practices and $50(46 \%)$ from a public hospital. Among the total prescriptions, $116(62.70 \%)$ were of male and $69(37.30 \%)$ of female. It was observed that majority of the patients $88(47.57 \%)$ belongs to the age group of 1 mo- $1 \mathrm{y}$ followed by $67(36.22 \%)$ patients from 1 y-5 y age group and $30(16.22 \%)$ patients from $5 \mathrm{y}-12 \mathrm{y}$ age group (table 1$)$.

Table 1: Demographic characteristics of patients

\begin{tabular}{lll}
\hline Variables & Number of patients & Percentage (\%) \\
\hline Prescriptions from private practitioner & 135 & $54 \%$ \\
Prescriptions from public hospital & 50 & $46 \%$ \\
Gender distribution & Number of patients & Percentage $(\%)$ \\
Male & 116 & $62.70 \%$ \\
Female & 69 & $37.30 \%$ \\
Age distribution & Number of patients & Percentage $(\%)$ \\
1 mo-1 y & 88 & $47.57 \%$ \\
$1-5 \mathrm{y}$ & 67 & $36.22 \%$ \\
$5-12 \mathrm{y}$ & 30 & $16.22 \%$ \\
\hline
\end{tabular}

The results of the study demonstrated that the ages were not mentioned in $4.3 \%$ and body weights were not written in $40 \%$ of the prescriptions. According to the study, physician's handwriting was not clear and legible in $50(27.03 \%)$ prescriptions. None of the drugs were prescribed by generic name rather, proprietary (brand) name were used. In our study, sign and symptoms and chief complaints were mentioned in 107 (57.84\%) prescriptions, whereas only 67 (36.22\%) patient's diseases were confirmed. The attitudes and behavior of physicians varies greatly depending on the settings. In hospital practices, patients' diagnosis of disease conditions were diagnosed on the basis of the chief complaints and diagnostic examinations; whereas in private practices, although chief complaints were written only in few cases diagnosis was confirmed.

Pediatric patients were mainly suffering from pneumonia, septicemia and meningitis. Pneumonia was the most commonly occurring disease $(24 \%)$ in the age group of 1 mo- $1 \mathrm{y}$ and was the leading cause of hospitalizations. Children between the age of $5 \mathrm{y}-12 \mathrm{y}$ were mostly $(18 \%)$ suffering from massive pleural effusion, acute glomerulonephritis, acute watery diarrhea, enteric fever and gastritis (table 2). This was probably due to the ingestion of contaminated food, drinking impure water and lack of proper nutrition at this age.

Table 2: Diagnosis pattern in different age group

\begin{tabular}{|c|c|c|c|c|}
\hline Diagnosis & 1mo-1y & $1 y-5 y$ & $5 y-12 y$ & No. \\
\hline S. Pneumonia & 7 & 2 & 1 & 10 \\
\hline S. Pneumonia with other Diseases & 5 & 1 & 0 & 6 \\
\hline Septicaemia & 6 & 0 & 0 & 6 \\
\hline Meningitis & 3 & 2 & 0 & 5 \\
\hline Combinations & 1 & 3 & 4 & 8 \\
\hline Others & 3 & 2 & 9 & 14 \\
\hline
\end{tabular}

Among 185 patients, a total 468 drugs were prescribed with an average of 2.53 drugs per prescription. The result of this study showed that more than $77 \%$ of the patients were exposed to multiple drug therapy of which two drugs were prescribed in $31.89 \%$, three drugs in $20 \%$, and even four drugs were advised in $20.54 \%$ prescriptions. Thus, it is evident that multiple drug therapy and overdosing are common in pediatric patients and the records were high in private practices. Different therapeutic classes of drugs such as NSAIDS 65 (35.14\%), anti-histamine 57 (30.81\%), antiasthmatic $49(26.49 \%)$ were accounted in prescriptions followed by vitamins and minerals 51 (27.57\%), steroids 57 (30.81\%) and hypnotics $26(14.05 \%)$ as shown in fig. 1.
The results showed that, the percentage of prescriptions with antibiotics was $93.5 \%$ of which $62.70 \%$ of prescriptions include a single antibiotic. Two antibiotics in $12.43 \%$ and three antibiotics in $2.16 \%$ of prescriptions were also given (fig.2).

Further, analysis of prescriptions revealed that pediatric patients were exposed to $23.5 \%$ and $50 \%$ of antibiotics in private practices and hospitals respectively. Among antibiotics, cephalosporin (45\%) was the most frequently prescribed by private practitioner followed by quinolone $(16 \%)$. On the other hand, in public hospital, penicillin $(42 \%)$ was the most frequently prescribed antibiotic, followed by cephalosporin (37\%). 


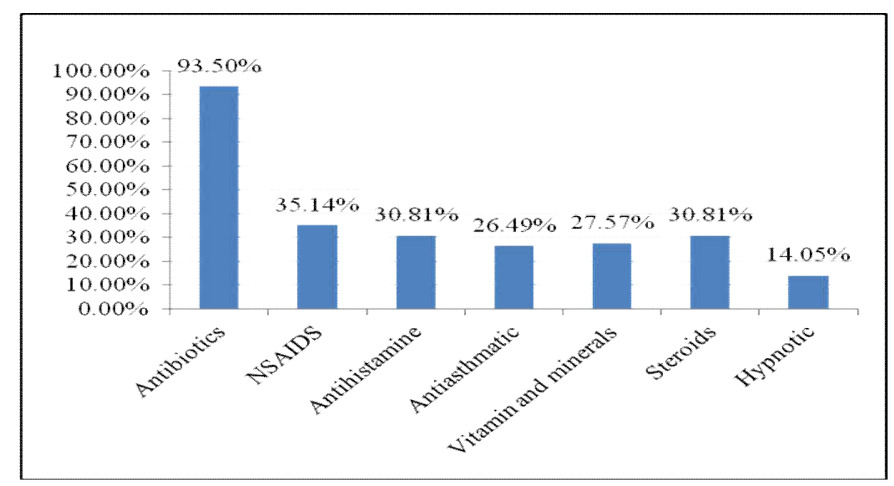

Fig. 1: Most common groups of drug prescribed

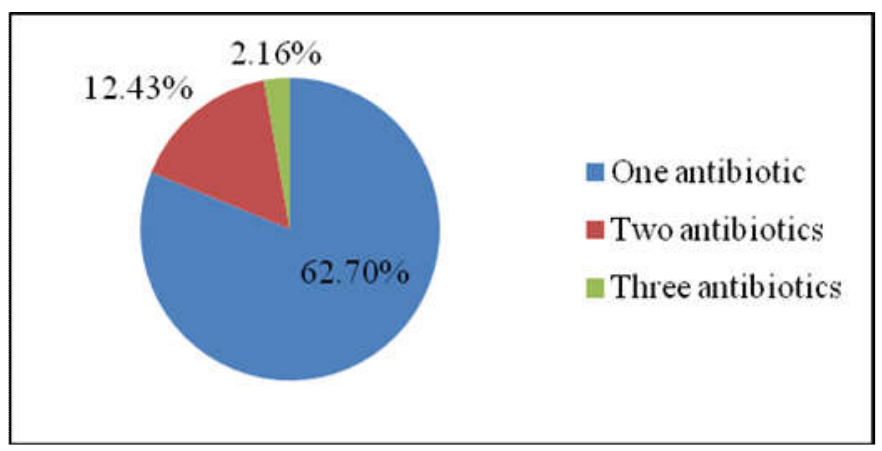

Fig. 2: Prescribing frequency of antimicrobials

Table 3: Assessment of WHO core drug use indicators

\begin{tabular}{ll}
\hline Characteristics & Value \\
\hline Total number of prescriptions & 185 \\
Total number of drugs prescribed & 468 \\
Average number of drugs per prescription & 2.53 \\
\% of drugs prescribed by generic name & 0 \\
\% of diagnosis for the disease & $67(36 \%)$ \\
\% of prescriptions containing antimicrobial agents & $93.5 \%(173)$ \\
\% of prescriptions with anti-inflammatory drugs & $65(35 \%)$ \\
\% of prescriptions with drugs for acid-related disorder & 0 \\
\hline
\end{tabular}

\section{DISCUSSION}

Irrational use of drugs is commonly observed in healthcare practices around the world and the prevalence is high in developing countries [18]. Inappropriate prescription not only increases the cost of therapy but also increases morbidity and mortality. Further, misuse or overuse of antibiotic can lead to the emergence of drug resistance. Irrational uses of antibiotics are highly prevalent among pediatric patients in Bangladesh. A prescription order written by a physician reflects his attitude towards the management of disease condition [19]. Therefore, the study was designed to analyze drug use patterns in pediatrics by physicians in private practice and public hospitals in Bangladesh.

The data revealed that none of the drugs were prescribed by generic name rather in the brand name. According to Bangladesh National Formulary (BDNF) physicians has the freedom to use either generic and/or brand name for prescriptions. However, the physicians mostly preferred brand name, possibly due to the aggressive marketing policies by the pharmaceutical manufacturer that offers physicians to write brands instead of generics. A study in India showed that $76 \%$ of the drugs were prescribed by generic name
[20]. It has been recognized that the substitution of brands by cheaper generic medicines can save up to $90 \%$ of the costs of medicine [21]. In fact, generic prescribing has to be encouraged in both private and hospital practices as it offers cheaper and affordable price for the patient and the chances of medication error would be less. According to WHO, the number of drug per prescription should be 2.0 [22] and which is very important in terms of effectiveness, safety and costs of therapy. In this survey, the average number of drugs prescribed was 2.53 and this finding was similar to that of the studies reported by Sturkenboom et al., which was 2.27 [23]. Recently, we conducted a survey and reported a higher rate 3.36 drugs per prescription in a government hospital in Bangladesh [24]. Although our present research represented a lower average drug per prescriptions, it was not ideal.

The results of our study indicated that more than $77 \%$ of the patients were exposed to multiple drug therapy and $40 \%$ of prescriptions advised three or four drugs, which was much higher than that reported earlier [20]. The multi-drug prescriptions resulted may be due to the fact that the treatment was initiated on the basis of symptoms rather than diagnostic tests. Our study reported $35 \%$ of NSAID drugs were used by patients and also 
multivitamins were advised in large quantities without any symptoms of nutritional deficiencies. Moreover, prescriptions of steroids and hypnotics could not be rationalized with the disease diagnosed. The physicians have to be careful while advising drugs for children since multi-drug prescriptions can lead to increased risk of drug interactions, development of resistance and increased cost of therapy $[25,26]$.

We found that the percentage of prescriptions with antibiotics was $93.5 \%$, which was very higher than that of WHO recommendations [27]. Previously, we reported that the use of antibiotics was $54 \%$ in Bangladesh whereas in India it varied from $40-80 \%[28,29]$. In private practices, antibiotics like penicilins, cephalosporins, macrolides and quinolones were prescribed without any specific diagnosis; whereas in hospital settings, most of the treatment was initiated after culture and sensitivity tests. Penicillin (42\%) was the most frequently prescribed in public hospitals and cephalosporin $(45 \%)$ was mostly prescribed by private practitioners, and thus, increased costs of treatment. We believe that the empirical use of antibiotics by the physicians resulted due to the lack of confidence, poor consulting time, misuses of bacteriological laboratory service and absence of policies on antimicrobial use. Further, antibiotics cost has been increased dramatically over the years with an overal trend to prescribe expensive broad-spectrum rather than narrowspectrum antibiotics for an extended period of time, resulting in bacterial resistance accompanied by therapeutic failure [30-32].

\section{CONCLUSION}

This study indicated that children and infants are at risk of receiving multiple courses of antibiotics and drugs. The main challenge in the prescription of antibiotics is to achieve a rational choice and appropriate use of antibiotics. Consequently, physicians must keep a clear understanding of the needs of bacteriological examination for diagnosis, use of antimicrobials and make a good judgment in clinical practice. The results of this study will help in rationalizing drug use, decreasing medication errors, improving therapeutic outcomes and ultimately form the basis for the development and implementation of effective policies to ensure appropriate medication in pediatric patients.

\section{LIMITATIONS}

The limitations of the study includes the data collected over a short period of time; the sample size was small, in very few cases culture/sensitivity tests were advised; and finally, no follow-up data could be obtained. Seasonal variation should be considered as it might have affected disease patterns and antibiotic use. The finding of the study is a representative one and cannot be generalized to the whole population of Bangladesh. However, the results provided future direction for examining trends in occurrence of infectious disease and therapeutic strategies for child populations.

\section{ACKNOWLEDGEMENT}

The authors are thankful to the Department of Pharmacy of Rajshahi University and also to the authority of RMCH and private clinics for supporting us to conduct this survey-based research work.

\section{FUNDING}

Nil

\section{AUTHORS CONTRIBUTIONS}

AU and SS: a collection of primary data, writing of the manuscript, and made critical revision for the manuscript; MM and CS: formulated the present hypothesis and coordination of the survey; TRP: responsible for analysis of the data and preparation of table and graphs; MIIW: supervision of the project, was responsible for writing the report and made critical revision for the manuscript. All of the authors have read and approved the final manuscript.

\section{CONFLICT OF INTERESTS}

The authors declare that they have no conflict of interests.

\section{REFERENCES}

1. Ginsberg G, Hattis D, Sonawane B, Russ A, Banati P, Kozlak M, et al. Evaluation of child/adult pharmacokinetic differences from a database derived from the therapeutic drug literature. Tox Sci 2002;66:185-200.

2. Takahashi H, Ishikawa S, Nomoto S, Nishigaki Y, Ando F, Kashima T, et al. Developmental changes in pharmacokinetics and pharmacodynamics of warfarin enantiomers in Japanese children. Clin Pharmacol Ther 2000;68:541-55.

3. Guyon AB, Barman A, Ahmed JU, Ahmed AU, Alam MS. A baseline survey on the use of drugs at the primary health care level in Bangladesh. Bull World Health Organ 1994;72:265-71.

4. Vallano A, Montane E, Arnau JM, Vidal XC, Pallare, Coll M. Medical specialty and pattern of medicines prescription. Eur J Clin Pharmacol 2004;60:725-30.

5. Ghai OP, Paul VK. Rational drug therapy in pediatric practice. Indian Pediatrics 1988;25:1095-109.

6. Faryna A, Wergowske GL, Goldenberg K. Impact of therapeutic guidelines on antibiotic use by residents in primary care clinics. J General Internal Med 1987;2:102-7.

7. Fedorak RAA, Flamm R, Osato M, Stamler D. Antimicrobial susceptibility of $\mathrm{H}$. pylori in Canada to three key antibiotics: metronidazole, clarithromycin, and amoxicillin. Gastroenterology 1997;112:115.

8. Nahar S, Mukhopadhyay AK, Khan R, Ahmad MM, Datta S, Chattopadhyay $\mathrm{S}$, et al. Antimicrobial susceptibility of Helicobacter pylori strains isolated in Bangladesh. J Clin Microbiol 2004;42:4856-8.

9. Paluck E, Katzenstein D, Frankish CJ, Herbert CP, Milner R, Speert D, et al. Prescribing practices and attitudes toward giving children antibiotics. Can Fam Physician 2001;47:521-7.

10. Andreasen F. Protein binding in plasma from patients with acute renal failure. Acta Pharmacol Toxicol 1973;32:417-29.

11. Hossain MM, Glass RI, Khan MR. Antibiotic use in a rural community in Bangladesh. Int J Epidemiol 1982;11:402-5.

12. Ratanawijitasin S. Drug users in Thailand: identifying problems and developing strategies for rational use of drugs. INRUD News 1996;6:21.

13. WHO. The rational use of drugs. Report of the Conference of Experts. Nairobi, 25-29 November 1985. Geneva, World Health Organization; 1987.

14. Laporte JR, Porta M, Capella D. Drug utilization studies: a tool for determining the effectiveness of drug use. Br J Clin Pharmacol 1983;16:301-4.

15. Tzimis L, Kafatos A. Drug utilization and nutrition patterns among children from indigent and emigrant families in Crete, Greece. Public Health 2000;114:393-7.

16. Hanne M, Morten A, Jesper H. Drug prescribing in Danish children: a population-based study: pharmacoepidemiology and prescription. Eur J Clin Pharmacol 2001;57:159-65.

17. Karande S, Sankhe P, Kulkarni M. Patterns of prescription and drug dispensing. Indian J Pediatrics 2005;72:117-21.

18. Melrose D. Double' deprivation public and private drug distribution from the perspective of the third world's poor. World Dev 1983;11:181-6.

19. Laporte JR. Towards a healthy use of pharmaceuticals. Deployment Dialogue 1995;2:48-55.

20. Balaji R, Sekkizhar M, Ashok Kumar M, Nirmala P. An observational study of drug utilization pattern and pharmacovigilance of antipsychotics. Int J Curr Pharm Res 2017;9:56-62.

21. Cameron A, Mantel Teeuwisse AK, Leufkens HG, Laing RO. Switching from originator brand medicines to generic equivalents in selected developing countries: how much could be saved? Value Health 2012;15:664-73.

22. Gross F. Drug utilization therapy and practice: the present situation in the federal republic of germany. Eur J Clin Pharmacol 1981;19:387-94.

23. Olsson J, Kimland E, Pettersson S, Odlind V. Pediatric drug use with a focus on off-label prescriptions in swedish outpatient care: a nationwide study. Acta Pediatr 2011;100:1272-5. 
24. Sumon Kumar Datta, Tripti Rani Paul, Monalisa Monwar, Ambia Khatun, M Rafiqul Islam, M Ashraf Ali, et al. Patterns of prescription and antibiotic use among outpatients in a tertiary care teaching hospital of Bangladesh. Int J Pharm Pharm Sci 2016;8:60-3.

25. Sridevi SA, Janagan T, Rathnasamy P, Rajarajeswari R. Drug utilization study in the otorhinolaryngology department in a tertiary care hospital. Int J Basic Clin Pharmacol 2013;2:306-10.

26. Padwal SL, Kulkarni MD, Deshmukh VS, Patil JR, Jadhav SS, Jadhav AD. Drug use pattern in the ear, nose, throat outpatient department of a rural tertiary care teaching hospital. Natl J Physiol Pharm Pharmacol 2015;5:212-6.

27. Najmi A, Verma A, Aiman U. Drug utilization study in the outpatient pediatric department of a tertiary care teaching hospital of district Lucknow. Asian J Pharm Clin Res 2015;8:327-30.

28. S KI, Chandy SJ, Jeyaseelan L, Kumar R, Suresh S. Antimicrobial prescription patterns for common acute infections in some rural and urban health facilities of India. Ind J Med Res 2008;128:165-71.

29. Ansari F. Use of systemic anti-infective agents in Iran 19971998. Eur J Clin Pharmacol 2001;57:547-51.

30. Mc Gowan JE. Antimicrobial resistance in hospital organisms and its relation to antibiotic use. Rev Infect Dis 1983;5:1033-48.

31. Murray BE. Can antibiotic resistance be controlled? N Engl J Med 1994;330:1229-30.

32. Joshi N, Milfred D. The use and misuse of new antibiotics: a perspective. Arch Intern Med 1995;155:569-77. 